\title{
Impact of genotype-first diagnosis: the detection of microdeletion and microduplication syndromes with cancer predisposition by aCGH
}

\author{
Sara Anne Adams, $M S^{l}$, Justine Coppinger, $M S^{l}$, Sulagna C. Saitta, MD, PhD ${ }^{2}$, Tracy Stroud, $M D^{3}$, \\ Manikum Kandamurugu, $\mathrm{MD}^{4}$, Zheng Fan, PhD ${ }^{4}$, Blake C. Ballif, PhD ${ }^{1}$, Lisa G. Shaffer, PhD ${ }^{1,5}$, \\ and Bassem A. Bejjani, $M D^{1,6,7}$
}

\begin{abstract}
Background: The use of microarray-based comparative genomic hybridization has allowed the genetic diagnosis of some conditions before their full clinical presentation. This "genotype-first" diagnosis has the most clinical implications for genomic alterations that confer an elevated risk of cancer. In these cases, diagnosis before the manifestation of the patient's full phenotype dramatically impacts genetic counseling, clinical management, and eventual prognosis and survivability. Methods: Using microarray-based comparative genomic hybridization, we tested 18,437 individuals with indications such as developmental disabilities and congenital anomalies. Results: We identified 34 (0.18\%) individuals with DNA copy number gains or losses that encompassed gene regions associated with recognized genetic conditions with an increased risk for cancer. Three of the 34 individuals $(8.8 \%)$ had a previously abnormal cytogenetic study which microarray-based comparative genomic hybridization confirmed and/or further characterized. Seven of the 34 individuals $(20.6 \%)$ either had the correct disease specified in the clinical indication for study or had clinical features highly indicative of that syndrome. The remaining 24 patients $(70.6 \%)$ had indications for study that were not specific to the diagnosed syndrome, such as "developmental delay" or "dysmorphic features." Conclusions: The ability of microarray-based comparative genomic hybridization to rapidly and objectively interrogate the genome for chromosomal imbalances has led to the opportunity to optimize medical management and outcome. This has an even more profound impact and clinical utility in conditions associated with cancer predisposition syndromes. Genet Med 2009:11(5):314-322.
\end{abstract}

Key Words: array CGH, comparative genomic hybridization, cancer, predisposition testing, mental retardation

M croarray-based comparative genomic hybridization (aCGH) has become an important cytogenetic diagnostic tool in the evaluation of patients with intellectual disabilities, developmental delays, birth defects, seizures, behavior disturbances, or aberrant growth patterns. aCGH has identified new

From the ${ }^{1}$ Signature Genomic Laboratories, LLC, Spokane, Washington; ${ }^{2}$ Division of Human Genetics, Children's Hospital of Philadelphia, Philadelphia, Pennsylvania; ${ }^{3}$ Thompson Center for Autism and Neurodevelopment Disorders, University of Missouri, Columbia, Missouri; ${ }^{4}$ Division of Pediatrics, Genetics and Metabolism, University of North Carolina, Chapel Hill, North Carolina; ${ }^{5}$ School of Molecular Biosciences, Washington State University; ${ }^{6}$ WWAMI Medical Education Program, Washington State University; and ${ }^{7}$ Sacred Heart Medical Center, Spokane, Washington.

Bassem A. Bejjani, MD, Signature Genomic Laboratories, LLC, 2820 N. Astor Street, Spokane, WA 99207. E-mail: bejjani@signaturegenomics.com.

Disclosure: L.G. Shaffer and B. A. Bejjani have ownership and sit on the Members' Board of Signature Genomic Laboratories, LLC.

Submitted for publication November 18, 2008

Accepted for publication February 9, 2009.

DOI: $10.1097 /$ GIM.0b013e3181a028a5 syndromes, ${ }^{1-4}$ expanded phenotypic spectrums of previously identified syndromes, ${ }^{5}$ elucidated the genomic basis of welldefined clinical syndromes, ${ }^{6}$ and refined molecular mechanisms of chromosomal aberrations identified by routine karyotyping. ${ }^{7}$

This technology is frequently used to assist in diagnosing patients without clinical findings suggestive of a specific structural chromosome disorder. ${ }^{8}$ Before the adoption of aCGH in diagnostic testing, the recommended cytogenetic evaluations for individuals with intellectual disability, developmental delay, birth defects, abnormalities in growth, seizures, or behavior differences such as autism consisted of karyotyping followed by subtelomeric fluorescence in situ hybridization (FISH). If clinical features increased suspicion for a specific microdeletion or microduplication syndrome, single-locus FISH could be pursued, but success in diagnosis depended on classic phenotypic presentation and the clinician's ability to recognize characteristic clinical features. In contrast to the "phenotype-first" approach of the past, aCGH expands upon the "genotype-first" approach of routine chromosome analysis and, more recently, subtelomeric FISH studies, by allowing a comprehensive objective interrogation of chromosome structure for microscopic and submicroscopic imbalances throughout the genome in individuals who may not exhibit recognizable phenotypic features of a specific disorder. ${ }^{9}$ This genotype-first approach allows for the diagnosis of genetic conditions in infants and children before the full manifestation of classic or recognizable clinical features to a greater extent than has ever been available in the past. Early diagnosis provides opportunities to refine medical management to optimize patient health and medical outcome.

One of the most dramatic examples of the clinical utility of aCGH and how this technology optimizes medical management is the diagnosis of genetic conditions that confer an increased risk of cancer. Many cancer syndromes have associated congenital anomalies that bring the child to clinical attention before the onset or suspicion of neoplasia. ${ }^{10,11}$ Although most mutations that cause cancer predisposition are sequence mutations within critical genes that would not be detectable by aCGH, many deletions have been reported of various cancer predisposition genes, such as PTEN, WTI, $R B 1$, and $A P C . .^{12,13}$ In addition, patients with deletions often have larger regions deleted than just the immediate gene, which can cause features more typical of chromosomal abnormalities, such as mental retardation, birth defects, and behavioral anomalies. ${ }^{14,15}$ Because of its utility in diagnosing individuals with nonspecific clinical findings, aCGH may detect DNA copy gains or losses that can predispose to neoplasm (Table 1). We report our experience with diagnosis of cancer syndromes using aCGH and present case examples to demonstrate how this genotype-first approach to diagnostic testing refines and guides medical management and improves clinical outcome. 


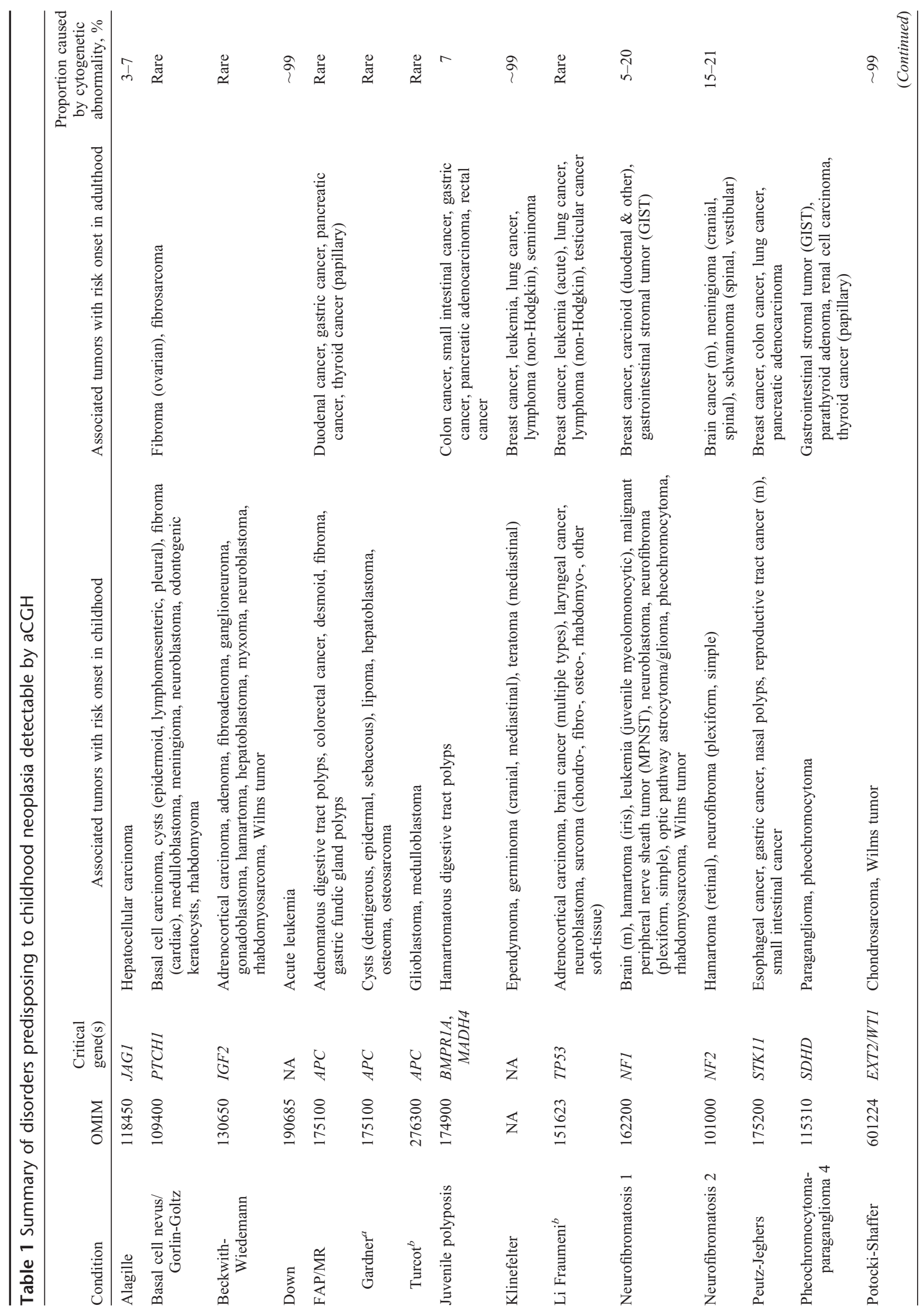




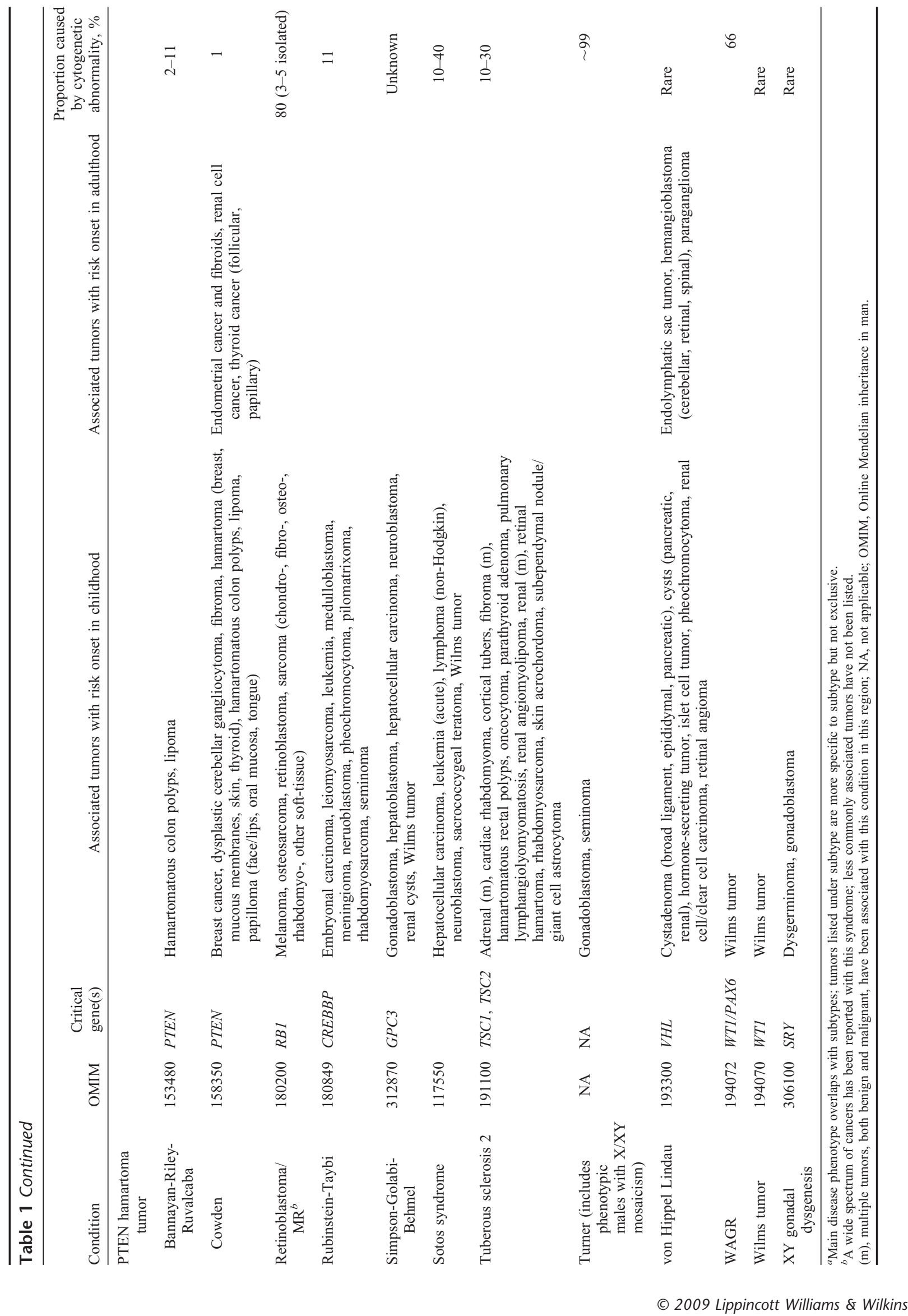




\section{MATERIALS AND METHODS}

\section{Patients}

From April 2004 to February 2008, we tested 18,437 individuals submitted to Signature Genomic Laboratories. The most common clinical presentations were mental retardation, developmental delay, or multiple congenital anomalies. Previous cytogenetic studies had been performed in some patients, with normal results in some and abnormal results in others (Table 2). In cases where abnormal results were identified by routine cytogenetics, aCGH was run in tandem with karyotyping or performed to characterize the identified abnormality further. Several subjects had previous normal FISH studies such as subtelomere FISH and/or locus-specific FISH.

\section{Microarray analysis}

aCGH was performed with a bacterial artificial chromosome (BAC) microarray (the SignatureChip ${ }^{\circledR}$; Signature Genomic Laboratories, Spokane, WA) that was developed for the detection of microdeletions, microduplications, aneuploidy, unbalanced translocations, and subtelomeric and pericentromeric copy-number alterations. ${ }^{16}$ The current version of the SignatureChip, the SignatureChip Whole Genome ${ }^{\circledR}$ (SignatureChipWG), contains 4670 BACs representing 1543 loci with each locus represented by a minimum of three overlapping clones. The subtelomeric and pericentromeric regions are represented with a higher density of overlapping BAC clones, targeted to the unique sequences adjacent to these repetitive regions and consisting of contigs of clones located approximately every $0.5 \mathrm{Mb}$ spanning $>5 \mathrm{Mb}$. Genes in important developmental pathways are also covered by contigs of BACs to fill in the chromosome arms and provide higher resolution with an average gap size between contigs of $\sim 1.6 \mathrm{Mb} .{ }^{17} \mathrm{Mi}$ croarray analysis was performed as described. ${ }^{17}$

\section{FISH analysis}

All abnormalities detected by aCGH were confirmed and visualized by metaphase or interphase FISH as published using one or more $\mathrm{BAC}$ clones determined to be abnormal by aCGH. ${ }^{18}$

\section{RESULTS}

We identified 34 patients with DNA copy-number gains or losses that encompassed gene regions associated with recognized cancer syndromes. Patients with numeric chromosome abnormalities are not included in this series. A summary of these patients by disorder, age of diagnosis by microarray, indication for testing, and location and size of chromosome alteration detected by aCGH is shown in Table 2 .

Of patients known to have karyotype results, 4 of 11 (36.4\%) had an abnormal cytogenetic study, which aCGH further characterized. An additional three patients $(27.3 \%)$ had routine chromosome analysis done at the same time as aCGH that identified a subtle abnormality consistent with the aCGH results. Four patients $(36.4 \%)$ had normal karyotyping results. At least two patients did not have karyotyping performed before or in conjunction with aCGH. Seven of the 34 patients $(20.6 \%)$ either had the correct disease specified in the clinical indication for study or had clinical features highly indicative of that syndrome (e.g., all three patients with Wilms tumor, aniridia, genitourinary anomalies, and mental retardation (WAGR) syndrome deletions had "aniridia" listed as the indication for study). The remaining 24 patients $(70.6 \%)$ had indications for study that were not specific to the diagnosed syndrome, such as "developmental delay," "dysmorphic features," or reference to specific clinical features that did not strongly indicate a particular syndrome. We present four case reports in detail.

Patient 1 is a $3 \frac{1}{2}$-year-old boy with global developmental delay, macrocephaly with ventriculomegaly, two café au lait spots, and vertebral anomalies. He had been followed by specialists from birth, when he was identified with possible ArnoldChiari malformation, mild hydronephrosis, and vertebral anomalies, including bifid ribs and T1 butterfly vertebra, all of which were attributed to maternal gestational diabetes. Brain magnetic resonance imaging (MRI) as a newborn demonstrated hydrocephalus. Because of strong suspicion of a genetic syndrome, he was evaluated at ages $3 \frac{1}{2}$ months, $1 \frac{1}{4}$ years, and again at $3 \frac{1}{2}$ years. Previous testing included chromosome analysis, subtelomeric FISH, and CPK, all of which were normal. aCGH at $3 \frac{1}{2}$ years identified a $3-\mathrm{Mb}$ interstitial deletion at 9q22.32q22.33 encompassing the $\mathrm{PTCH} 1$ gene region (Fig. 1A). FISH testing using a BAC clone encompassing the PTCH1 gene confirmed the deletion (Fig. 1B). A repeat MRI performed concurrent with aCGH testing confirmed ventriculomegaly and identified an enlarged pineal gland of increased signal intensity. On receipt of the abnormal aCGH test results, consultations were arranged with cardiologists to evaluate for cardiac fibromas, dermatologists to evaluate for basal cell nevi, ophthalmologists to evaluate for eye anomalies such as cataracts and retinal epithelium pigmentary changes, a pediatric dentist to evaluate for jaw keratosis, and neurologists to address the abnormal MRI findings. A follow-up evaluation found the enlarged pineal gland to be a pineal tumor, which is being monitored closely with no invasive procedure planned. The family was counseled and given literature and contacts for support services for GorlinGoltz/Basal cell nevus syndrome.

Patient 2 was previously reported by Heald et al. ${ }^{12}$ The patient is a 22-year-old woman who was referred to the genetics clinic with features suggestive of Prader-Willi syndrome, including short stature, intellectual disability, obesity, hypotonia, and small hands and feet. The patient was adopted and pregnancy and family history are unknown. Her medical history included hypotonia as an infant, a diagnosis of epilepsy at the age of 2 years, and onset of obesity around 7-8 years of age without hyperphagia. Multiple mild dysmorphic features were noted on examination. Previous genetics workup included chromosome analysis and DNA methylation studies for Prader-Willi syndrome, both of which were normal. aCGH identified a 1.8-Mb interstitial deletion at 5q22.1q22.2 encompassing the $A P C$ gene and surrounding region. FISH testing using a BAC clone encompassing the $A P C$ gene confirmed the deletion. Subsequent colonoscopy identified hundreds of adenomatous polyps; biopsies were negative for malignancies by pathologic examination. A colectomy with ileorectal anastomosis was undertaken to prevent future colorectal cancer. An upper endoscopy identified $>50$ sessile polyps in her stomach and duodenum and a slight papillary enlargement in the duodenum. A thyroid ultrasound identified bilateral nodules and a resulting biopsy demonstrated papillary thyroid cancer. The cancer was treated with thyroidectomy and subsequent iodine-131 therapy.

Patient 3 is a 5-year-old boy with developmental delays, subnormal intelligence quotient, autism, speech delays, behavior problems, clumsiness, and insomnia. He has a history of sudden speech loss and right facial droop at the age of 13 months. At 2 years, he experienced left-sided upper and lower extremity weakness. The findings of subsequent electroencephalogram and MRI were normal. Previous testing included an electroencephalogram and brain MRI, the findings of both of which were normal. Karyotyping and $\mathrm{aCGH}$ were ordered con- 
Table 2 Summary of individuals identified in our study population with copy-number imbalances of regions associated with cancer syndromes

\begin{tabular}{|c|c|c|c|c|c|c|c|}
\hline $\begin{array}{l}\text { Cancer } \\
\text { syndrome }\end{array}$ & $\begin{array}{l}\text { Gene(s) } \\
\text { of interest }\end{array}$ & $\begin{array}{l}\text { Patient } \\
\text { number }\end{array}$ & $\begin{array}{l}\text { Age at aCGH } \\
\text { diagnosis }\end{array}$ & Indication for study & $\begin{array}{l}\text { Chromosome } \\
\text { location }\end{array}$ & $\begin{array}{l}\text { DNA dosage } \\
\text { abnormality }\end{array}$ & Inheritance \\
\hline \multirow{4}{*}{$\begin{array}{l}\text { Familial } \\
\text { adenomatous } \\
\text { polyposis }\end{array}$} & \multirow[t]{4}{*}{$A P C$} & & $4.5 \mathrm{yr}$ & Not specified & $5 \mathrm{q} 22.2 \mathrm{q} 22.3$ & $10.3 \mathrm{Mb}$ loss & De novo \\
\hline & & Patient 3 & $5 \mathrm{yr}$ & dd & $5 \mathrm{q} 22.1 \mathrm{q} 22.2$ & $1.7 \mathrm{Mb}$ loss & De novo \\
\hline & & & $14 \mathrm{yr}$ & dd & $5 \mathrm{q} 22.1 \mathrm{q} 22.2$ & $12.9 \mathrm{Mb}$ loss & De novo \\
\hline & & Patient 2 & $21 \mathrm{yr}$ & $\begin{array}{l}\text { Short stature, Prader-Willi } \\
\text { phenotype }\end{array}$ & $5 \mathrm{q} 22.1 \mathrm{q} 22.2$ & 5.6 Mb loss & Unknown \\
\hline $\begin{array}{l}\text { Juvenile } \\
\text { polyposis }\end{array}$ & $B M P R 1 A$ & & 8 days & $\begin{array}{l}\text { Bilateral hearing loss, } \\
\text { club feet }\end{array}$ & $10 \mathrm{q} 23.1 \mathrm{q} 23.2$ & $5.1 \mathrm{Mb}$ loss & De novo \\
\hline \multirow{4}{*}{$\begin{array}{l}\text { Beckwith- } \\
\text { Wiedeman }^{a}\end{array}$} & \multirow[t]{4}{*}{$I G F-2$} & & $8 \mathrm{mo}^{b}$ & $\mathrm{df}$ & $11 \mathrm{p} 15.5 \mathrm{p} 15.4$ & 1.3 Mb gain & De novo \\
\hline & & & $1.5 \mathrm{mo}^{c}$ & df & $11 \mathrm{p} 15.5$ & $2.3 \mathrm{Mb}$ gain & Unknown \\
\hline & & & $1.5 \mathrm{mo}$ & df, partial duplication $11 p$ & $11 \mathrm{p} 15.5 \mathrm{p} 13$ & $32 \mathrm{Mb}$ gain & Unknown \\
\hline & & & $2 \mathrm{yr}$ & $\mathrm{dd}$ & $11 \mathrm{p} 15.5 \mathrm{p} 15.2$ & $12.9 \mathrm{Mb}$ gain & De novo \\
\hline \multirow{5}{*}{$\begin{array}{l}\text { Gorlin-Goltz/ } \\
\text { Basal cell } \\
\text { nevus }\end{array}$} & \multirow[t]{5}{*}{ PTCH1 } & & 10 days & df & $9 \mathrm{q} 22.32 \mathrm{q} 22.33$ & 7.4 Mb loss & Unknown \\
\hline & & & $4.5 \mathrm{mo}$ & $\begin{array}{l}\text { dd, df, } 46, X X, \operatorname{inv}(9)(q 12 ; \\
\text { q21) }\end{array}$ & $9 \mathrm{q} 22.32 \mathrm{q} 22.33$ & $9.5 \mathrm{Mb}$ loss & Unknown \\
\hline & & & $1 \mathrm{yr}$ & $\begin{array}{l}\mathrm{dd}, \mathrm{df}, \text { macrocephaly, } \\
\text { hydrocephalus }\end{array}$ & 9q22.32 & $10.9 \mathrm{Mb}$ loss & De novo \\
\hline & & Patient 1 & $3.5 \mathrm{yr}$ & $\mathrm{dd}, \mathrm{df}$ & $9 \mathrm{q} 22.32 \mathrm{q} 22.33$ & $3 \mathrm{Mb}$ loss & Unknown \\
\hline & & & $12 \mathrm{yr}$ & $\mathrm{dd}, \mathrm{df}$ & $9 \mathrm{q} 22.32 \mathrm{q} 22.33$ & 13.2 Mb loss & Unknown \\
\hline \multirow[t]{7}{*}{ Neurofibromatosis 1} & \multirow[t]{7}{*}{$N F 1$} & & $4 \mathrm{mo}$ & $\begin{array}{l}\text { Anomalies of skull and } \\
\text { face bones }\end{array}$ & $17 \mathrm{q} 11.2$ & $2.4 \mathrm{Mb}$ loss & Unknown \\
\hline & & & $1 \mathrm{yr}$ & cardiac anomaly & $17 \mathrm{q} 11.2$ & $0.82 \mathrm{Mb}$ loss & Unknown \\
\hline & & & $1 \mathrm{yr}$ & $\mathrm{dd}, \mathrm{df}$ & $17 \mathrm{q} 11.2$ & $0.82 \mathrm{Mb}$ loss & De novo \\
\hline & & & $3 \mathrm{yr}$ & dd, lack of coordination & $17 \mathrm{q} 11.2$ & $0.82 \mathrm{Mb}$ loss & De novo \\
\hline & & & $3 \mathrm{yr}$ & $\mathrm{dd}, \mathrm{df}$ & $17 \mathrm{q} 11.2$ & $0.82 \mathrm{Mb}$ loss & De novo \\
\hline & & & $3.5 \mathrm{yr}$ & $\begin{array}{l}\mathrm{dd} \text {, metabolic } \\
\text { encephalopathy }\end{array}$ & $17 \mathrm{q} 11.2$ & 3.9 Mb loss & De novo \\
\hline & & & $18 \mathrm{yr}$ & $\mathrm{dd}, \mathrm{df}, \mathrm{NF} 1$ & $17 \mathrm{q} 11.2$ & $6.8 \mathrm{Mb}$ loss & Unknown \\
\hline \multirow[t]{3}{*}{ Retinoblastoma/MR } & \multirow[t]{3}{*}{$R B 1$} & \multirow[t]{3}{*}{ Patient 4} & 12 days & $\mathrm{df}$ & $13 \mathrm{q} 13.3 \mathrm{q} 31.2$ & $51 \mathrm{Mb}$ loss & De novo \\
\hline & & & $1 \mathrm{yr}^{d}$ & dd, df, retinoblastoma & $13 \mathrm{q} 14.2$ & $21.2 \mathrm{Mb}$ loss & Maternal $^{d}$ \\
\hline & & & $20 \mathrm{yr}$ & $\begin{array}{l}\text { Unspecified mental } \\
\text { retardation }^{e}\end{array}$ & $13 \mathrm{q} 14.2$ & $1.8 \mathrm{Mb}$ loss & Unknown \\
\hline \multirow[t]{6}{*}{ Rubenstein-Taybi } & \multirow[t]{6}{*}{$C R E B B P$} & & 11 days & $\begin{array}{l}\text { Hydrocephalus, rule out } \\
\text { aneuploidy }\end{array}$ & $16 \mathrm{p} 13.3$ & $800 \mathrm{~kb}$ loss & Unknown \\
\hline & & & 20 days & $\mathrm{df}$ & $16 \mathrm{p} 13.3$ & $194 \mathrm{~kb}$ loss & Unknown \\
\hline & & & $1.5 \mathrm{mo}$ & Known $16 \mathrm{p}$ deletion & $16 \mathrm{p} 13.3$ & $1.7 \mathrm{Mb}$ loss & Unknown \\
\hline & & & $4 \mathrm{yr}$ & Not specified & $16 \mathrm{p} 13.3$ & $433 \mathrm{~kb}$ loss & Unknown \\
\hline & & & $12 \mathrm{yr}$ & $\begin{array}{l}\text { dd, df, possible Rubenstein } \\
\text { Taybi }\end{array}$ & $16 \mathrm{p} 13.3$ & $194 \mathrm{~kb}$ loss & Unknown \\
\hline & & & $15 \mathrm{yr}$ & $\mathrm{dd}, \mathrm{df}$ & $16 \mathrm{p} 13.3$ & $194 \mathrm{~kb}$ loss & $\begin{array}{l}\text { Unknown } \\
\text { (Continued) }\end{array}$ \\
\hline
\end{tabular}




\begin{tabular}{|c|c|c|c|c|c|c|c|}
\hline $\begin{array}{l}\text { Cancer } \\
\text { syndrome }\end{array}$ & $\begin{array}{l}\text { Gene(s) } \\
\text { of interest }\end{array}$ & $\begin{array}{l}\text { Patient } \\
\text { number }\end{array}$ & $\begin{array}{c}\text { Age at aCGH } \\
\text { diagnosis }\end{array}$ & Indication for study & $\begin{array}{c}\text { Chromosome } \\
\text { location }\end{array}$ & $\begin{array}{l}\text { DNA dosage } \\
\text { abnormality }\end{array}$ & Inheritance \\
\hline $\begin{array}{l}\text { Tuberous } \\
\text { sclerosis } 2\end{array}$ & $T S C 2$ & & $10 \mathrm{mo}^{f, g}$ & $\begin{array}{l}\text { Hyperteloric, ash-leaf spots, } \\
\text { VSD, cardiac } \\
\text { rhabdomyoma }\end{array}$ & $16 \mathrm{p} 13.3$ & $1.9 \mathrm{Mb}$ loss & Unknown \\
\hline \multirow[t]{3}{*}{ WAGR } & \multirow[t]{3}{*}{$P A X 6, W T 1$} & & 10 days & $\begin{array}{l}\text { df, anirida, horseshoe } \\
\text { kidney }\end{array}$ & $11 \mathrm{p} 14.1 \mathrm{p} 13$ & $3.3 \mathrm{Mb}$ loss & De novo \\
\hline & & & $4 \mathrm{mo}$ & Aniridia & $11 \mathrm{p} 14.1 \mathrm{p} 13$ & $6.2 \mathrm{Mb}$ loss & Unknown \\
\hline & & & $4 \mathrm{mo}$ & Aniridia & $11 \mathrm{p} 14.1 \mathrm{p} 13$ & 11.3 Mb loss & Unknown \\
\hline \multicolumn{8}{|c|}{$\begin{array}{l}{ }^{a} \text { DNA dosage gains cause BWS if paternally derived; parent of origin studies necessary. } \\
{ }^{b} \text { Unbalanced translocation }(11 ; 17) \text { ish } \operatorname{der}(17) \mathrm{t}(11 ; 17)(\mathrm{p} 15.4 ; \mathrm{p} 13.3)(\mathrm{RP} 11-542 \mathrm{~J} 6+; \mathrm{RP} 13-640 \mathrm{~F} 18-) \text { with terminal duplication } 17 \mathrm{p} \text {. } \\
\left.{ }^{c} \text { Unbalanced translocation }(4: 11) \text { ish } \operatorname{der}(4) \mathrm{t}(4 ; 11)(\mathrm{p} 16.3 ; \mathrm{p} 15.4)(\mathrm{RP} 11-1150 \mathrm{~B} 4-), \mathrm{RP} 11-542 \mathrm{~J} 6+\right) \text { with } 4 \mathrm{p} \text { terminal deletion of Wolf-Hirschhorn critical regions. } \\
{ }^{d} \mathrm{FISH} \text { analysis on mother found an apparently balanced insertion of } 13 \mathrm{q} 14.2 \text { region into } 10 \mathrm{q} \text {. } \\
{ }^{e} \text { Patient had a known } \mathrm{t}(1 ; 13) \text { that had been considered unrelated to phenotype. } \\
{ }^{f} \text { Unbalanced translocation }(16 ; 19) \text { ish der }(16) \mathrm{t}(16 ; 19)(\mathrm{p} 13.3 ; \mathrm{q} 13.43)(\mathrm{RP} 11-161 \mathrm{M} 6-\text {, RP11-126M21+). } \\
{ }^{g} \text { Additional FISH analysis using } 8 \text { fosmid clones defined } 16 \mathrm{p} 13.3 \text { deletion breakpoint } 35.8 \mathrm{~Kb} \text { distal to } T S C 2 \text { gene, suggestive of position effect. } \\
\text { dd, developmental delay; df, dysmorphic features. }\end{array}$} \\
\hline
\end{tabular}

currently. aCGH detected a $1.7-\mathrm{Mb}$ interstitial deletion at $5 \mathrm{q} 22.1 \mathrm{q} 22.2$ encompassing the $A P C$ gene and surrounding region (Fig. 1C; FISH testing using a BAC clone encompassing the $A P C$ gene confirmed the deletion (Fig. 1D). The karyotype was normal. On the basis of the aCGH findings, subsequent $\alpha$-fetoprotein testing and liver ultrasound to rule out hepatoblastoma secondary to $A P C$ gene deletion were normal. The patient then underwent an esophagogastroduodenoscopy, the results of which were negative. A colonoscopy was performed because of parental concern, the results of which were also negative.

Patient 4 is a 7-month-old girl born to a G1P1 mother after a full-term unremarkable gestation. She presented with poor feeding, overlapping toes, poor central muscle tone, and dysmorphic features including brachycephaly, upslanted palpebral fissures, deep-set and wide-spaced eyes, upturned nose, and a flat and smooth philtrum. She had abnormal head and foot movements suggestive of seizures. Family history was noncontributory. Blood was drawn on day 5 of life for concurrent karyotyping and aCGH. Preliminary aCGH results reported on day 8 of life demonstrated an $\sim 51-\mathrm{Mb}$ interstitial deletion of $13 \mathrm{q} 13.3 \mathrm{q} 31.2$ (Fig. 1E). FISH testing using a BAC clone encompassing the $R B 1$ gene confirmed the deletion, reported as a preliminary result to the ordering physician on day 9 , and as a final result demonstrating mosaic deletion in 27 of 30 cells on day 12 of life (Fig. 1F). Chromosome analysis revealed concordant results on day 12 of life. Subsequent to the abnormal preliminary results on day 8 of life a brain MRI was interpreted as abnormal with findings consistent with premature brain development. The findings of an opthalmological examination were normal. A hospital care conference was arranged on day 9 , attended by parents and specialists from ophthalmology, neurology, genetics, and developmental pediatrics. Seizure medications, early intervention, physical therapy, and feeding therapy were initiated. Arrangements were made for the patient to be followed by ophthalmology, neurology, and developmental pediatrics. At a scheduled follow-up ophthalmologic examination at 26 days of life, four tumors of $\sim 2-3 \mathrm{~mm}$ diameter were identified in the left eye. Chemotherapy was initiated. At 7 months follow-up, the patient was in good health with good weight gain, having completed a 4-month regimen of chemotherapy.

\section{DISCUSSION}

Numerous cancer syndromes can be diagnosed in childhood because of the presence of associated clinical features such as aniridia or specific dermatologic features that are recognized early, or because of the frank presentation of neoplasia in childhood (Table 1). For most conditions, most cases are caused by sequence mutations that are not detectable by aCGH. However, microdeletions and microduplications have been reported in some cases.

The genotype-first approach of aCGH allows for diagnosis of genetic syndromes at an early age that otherwise may not be diagnosed until onset of symptoms later in life. Of the 34 patients discovered to have aCGH findings associated with a described cancer syndrome, 27 of $34(79.4 \%)$ were 5 years old or younger at the time of aCGH diagnosis. Of these, two had no indication for study provided. In review of the indications for study for the remaining patients aged 5 years or younger, 10 of $25(40.0 \%)$ revealed suspicion for the diagnosis either by a previously discovered chromosome abnormality or reported phenotype consistent with the condition, and 15 of $25(60.0 \%)$ provided no indication that the diagnosis was suspected before aCGH analyses. For example, six of seven $(85.7 \%)$ cases with deletion of the NF1 gene region were detected in patients younger than 4 years without indication that neurofibromatosis was suspected clinically. Likewise, four of five $(80 \%)$ of cases with deletion of the PTCH1 gene region were younger than 4 years, with one case reported to have a previous chromosome abnormality of inversion of $9 q$, and one case reported to have hydrocephalus and macrocephaly, but otherwise no indication was provided of suspicion for diagnosis of Gorlin-Goltz/Basal cell nevus syndromes. Although clinicians may have had some level of suspicion for clinical diagnoses in these patients, based on information provided at the time of testing these patients were unlikely to have been accurately diagnosed at the time of examination based on clinical features alone.

With the penetrance of life-threatening eye tumors in the first year of life approaching $100 \%$, one would expect most patients with deletion of the $R B 1$ gene region on chromosome $13 \mathrm{q}$ to develop at least one retinoblastoma before age 2 years. ${ }^{19}$ Two of the three cases that we report were diagnosed by aCGH at the 
A

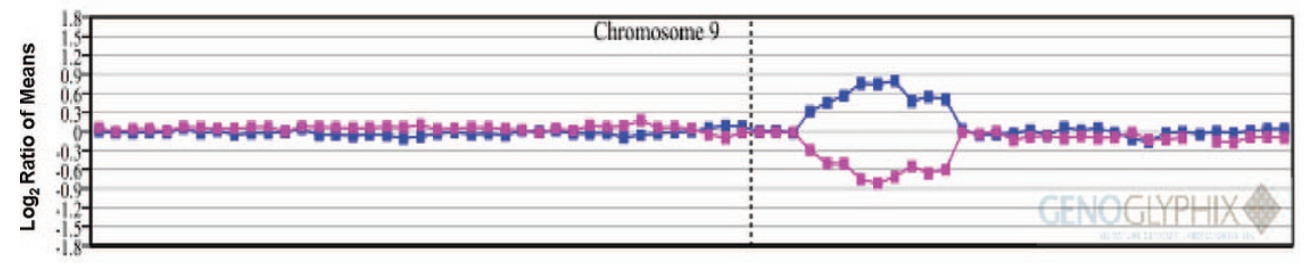

C

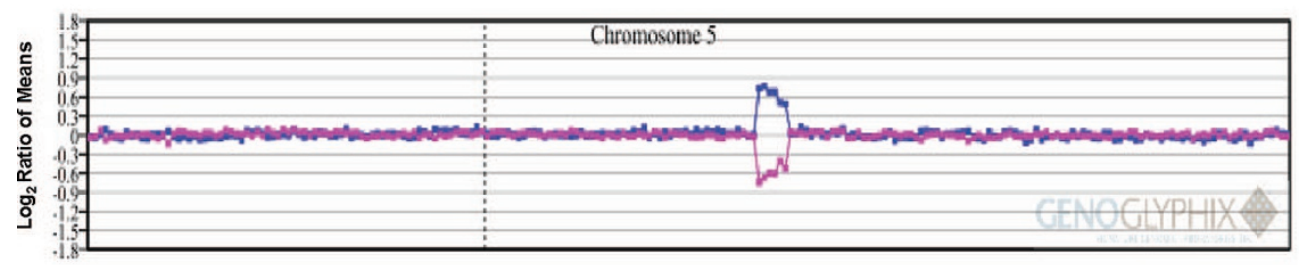

E

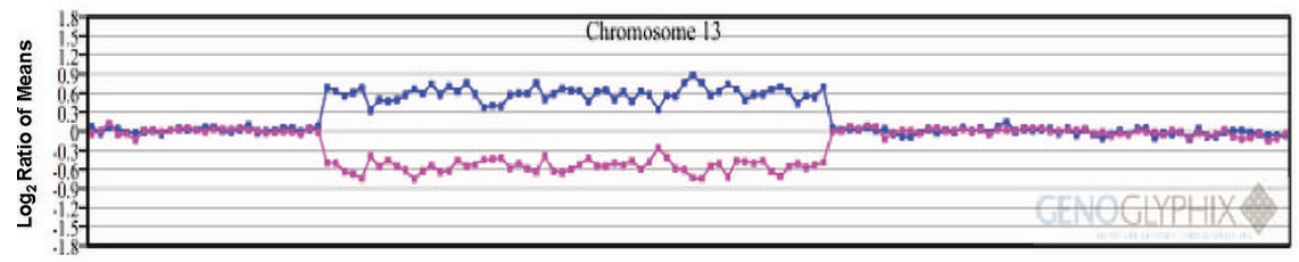

B

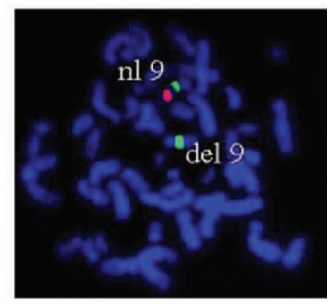

D

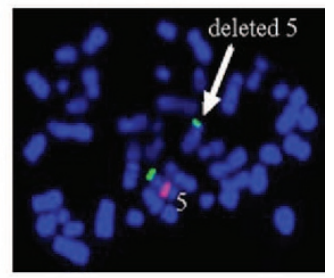

$\mathbf{F}$

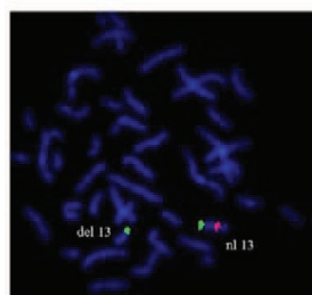

Fig. 1. Detection of copy-number losses of gene regions associated with recognized genetic conditions with an increased risk for pediatric neoplasm by aCGH and FISH. A, Microarray analysis for Patient 1 showing a single-copy loss at $9 q 22.32 q 22.33, \sim 3 \mathrm{Mb}$ in size. Each clone represented on the array is arranged along the $x$-axis according to its location on chromosome 9 with the most distal/telomeric $p$-arm clones on the left and the most distal/telomeric q-arm clones on the right. The blue line represents the ratios for each clone from the first experiment (control Cy5/patient Cy3), and the pink line represents the ratios for each clone obtained from the second experiment in which the dyes have been reversed (Patient Cy5/Control Cy3). B, FISH demonstrating deletion at 9q22.32. Probe RP11-916J1 from 9q22.32 is labeled in red and chromosome 9 centromere probe D9Z1 is labeled in green as a control. C, Microarray analysis for Patient 3 showing a single-copy loss of six BAC clones at $5 \mathrm{q} 22.1 \mathrm{q} 22.2 \sim 1.7 \mathrm{Mb}$ in size. Clones for chromosome 5 are arranged on the plot as in (A). D, FISH demonstrating deletion of a probe from the APC locus (RP11-107C15), labeled in red. The 5p subtelomere probe RP11-1006P13) is labeled in green as a control. E, Microarray analysis for Patient 4 showing a single-copy loss of 58 BAC clones at $13 q 13.3 q 31.2, \sim 51.1 \mathrm{Mb}$ in size. Clones for chromosome 13 are arranged on the plot as in (A). F, FISH demonstrating deletion of a probe to the RB1 locus at 13q14.2, labeled in red. 13q subtelomere probe RP11-569D9 is labeled in green as a control.

age of 1 year or younger, one case before onset of symptoms, and the other with retinoblastoma as a clinical indication for study. The third patient was diagnosed at 20 years; the ordering clinician had limited clinical information because this patient was lost to follow-up for many years, and early childhood medical records were not available at the time of aCGH testing. This patient had a known translocation involving chromosome 13; however, the clinical implications of this translocation had not been considered until the aCGH result showed $R B 1$ deletion.

The ability of aCGH to rapidly identify chromosome imbalances, accurately estimate chromosome alteration sizes, and allow for further characterization with FISH can expedite diagnosis, management, and parental counseling. In Patients 1 and 2 , the diagnosis of a cancer predisposition aided a timely cancer diagnosis, and in both cases, the deletion was too small to be identified by karyotyping. Having the diagnosis of a cancer predisposition condition may have saved the lives of these patients, and at a minimum allowed for cancer detection in Patient 1 much sooner than would have been possible otherwise. In Patient 1, although MRI was performed independently of the aCGH testing, the early genetic diagnosis may have helped determine that the enlarged pineal gland with increased signal intensity was not a benign finding, and therefore played a direct role in the early diagnosis of cancer that may have been postponed without aCGH. In addition, discovery of the previously unidentified genetic cause allowed access to support resources, including the opportunity for Patient 1 to connect with others with the diagnosis of Gorlin-Goltz syndrome and for Patient 1 to gain supplemen- 
tal security income, which she had been unable to obtain before diagnosis.

Patient 3, who has deletion of the APC gene region causing familial adenomatous polyposis, does not have a diagnosis of cancer, but has a lifetime cancer risk of nearly $100 \%$. Without early diagnosis there would have been no indication to perform colonoscopy and appropriate familial adenomatous polyposis surveillance.

For Patient 4, the genetic diagnosis was attained more quickly with aCGH than with karyotype analysis. The rapid provision of genetic information allowed for nearly immediate evaluations by ophthalmologic and neurologic specialists that were critical to patient care. In addition, the timely assembly of a team of specialists by day 9 to meet with parents in a care conference and develop a management plan optimized communication among both clinicians and family. Although karyotype results several days later would have clearly allowed for most of these early planning steps in this patient, the ability to provide unambiguous counseling as early as possible aids in the coping process for the family. Furthermore, without the aCGH results, karyotype results would have likely been less clear and required additional studies to provide conclusive results, adding additional time to the testing process. This case provides a useful example of how the two technologies complement one another.

Although cancer was not the primary clinical feature affecting any of these four patients before aCGH testing, the screening initiated because of an unexpected, genotype-first diagnosis has proven to be critical to their health and longevity. In all cases, the genetic diagnosis led to immediate referrals to a team of specialists. In Patients 2 and 4, immediate and necessary life-saving intervention was made possible by the timely diagnosis. In Patients 1 and 3, medical management was revised to include preventative cancer screening. The benefit of genetic diagnosis is not unique to these four patients. On the basis of the indications for aCGH analysis, only about $40 \%$ of the young patients referred for testing were suspected to have the cancerpredisposing diagnosis based on clinical features or previous karyotyping. Without aCGH testing, the remaining 60\% may have gone undiagnosed or had diagnoses delayed until a critical and potentially fatal clinical feature, such as cancer, developed.

Although these examples highlight the benefits of the genotype-first diagnostic approach, discovery of a genetic condition that confers a risk for cancer raises a number of genetic counseling challenges, particularly in a pediatric setting. When a diagnostic test for developmental delays, intellectual disabilities, birth defects, or other clinical findings unexpectedly identifies a genetic condition with a predisposition for cancer, the diagnosis can overwhelm a family. Not only must the family cope with a more concrete explanation for the collection of clinical features in the patient, the family is faced with the added medical, emotional, and psychological complexities of learning that there is also a risk for cancer. Consequently, test results can be difficult for families to process and comprehend. Although comprehensive pretest counseling regarding all possible outcomes of aCGH testing is not practical from the standpoint of time limitations and the likelihood of overwhelming parents, a general discussion of implications that could result from abnormal aCGH results is certainly feasible in most situations. This anticipatory guidance can help prepare families for possibilities they may come across without overwhelming them with information. Without this information, the families may be left to receive shocking news that their child, already found to have differences in development, intelligence, growth, or other medical issues, is also predisposed to cancer without any preparation for that possibility.
Another genetic counseling issue that may arise with aCGH testing is the inadvertent discovery of a familial cancer syndrome. Most of the conditions identifiable by aCGH and known to have cancer predisposition occur as de novo events. However, a few of these conditions, such as neurofibromatosis 1 or PTEN hamartoma tumor syndrome, may be passed through multiple generations. Identification of the cause of the child's condition may unexpectedly identify a familial cancer predisposition because a parent has either a balanced form of the child's rearrangement or the same abnormality as the child. Although these scenarios require skillful genetic counseling with balanced attention to issues specific to cancer, they are similar to the identification of a chromosome imbalance in a child that is subsequently also found in a parent, sibling, or other relative in either a balanced or unbalanced form. These possible aCGH outcomes are reminders to the clinician that taking a detailed family history before testing, providing appropriate pretest and posttest counseling, and following up with parental studies are critical components of the genetic testing process. As aCGH technology continues to advance, it will be important for the testing laboratory and ordering clinicians, genetic counselors, and other specialists involved in the circle of care of these patients to recognize the benefits and limitations of aCGH testing and counsel patients and families appropriately.

\section{ACKNOWLEDGMENTS}

We thank Aaron Theisen (Signature Genomic Laboratories) for editing our manuscript and Steve Byerly (Signature Genomic Laboratories) for analysis of the aCGH results.

\section{REFERENCES}

1. Ballif BC, Hornor SA, Jenkins E, et al. Discovery of a previously unrecognized microdeletion syndrome of 16p11.2-p12.2. Nat Genet 2007;39:10711073 .

2. Koolen DA, Vissers LE, Pfundt R, et al. A new chromosome 17q21.31 microdeletion syndrome associated with a common inversion polymorphism. Nat Genet 2006;38:999-1001.

3. Sharp AJ, Hansen S, Selzer RR, et al. Discovery of previously unidentified genomic disorders from the duplication architecture of the human genome. Nat Genet 2006;38:1038-1042.

4. Shaw-Smith C, Pittman AM, Willatt L, et al. Microdeletion encompassing MAPT at chromosome $17 \mathrm{q} 21.3$ is associated with developmental delay and learning disability. Nat Genet 2006;38:1032-1037.

5. Lawson-Yuen A, Wu BL, Lip V, Sahoo T, Kimonis V. Atypical cases of Angelman syndrome. Am J Med Genet A 2006;140:2361-2364.

6. Vissers LE, van Ravenswaaij CM, Admiraal R, et al. Mutations in a new member of the chromodomain gene family cause CHARGE syndrome. Nat Genet 2004;36:955-957.

7. Gajecka M, Peterson KL, Shaffer LG. Monosomy 1p36 deletion syndrome. Am J Med Genet C Semin Med Genet 2007;145:346-356.

8. Shaffer LG, Kashork CD, Saleki R, et al. Targeted genomic microarray analysis for identification of chromosome abnormalities in 1500 consecutive clinical cases. J Pediatr 2006;149:98-102.

9. Shaffer LG, Theisen A, Bejjani BA, et al. The discovery of microdeletion syndromes in the post-genomic era: review of the methodology and characterization of a new $1 \mathrm{q} 41 \mathrm{q} 42$ microdeletion syndrome. Genet Med 2007;9:607-616.

10. Lindor NM, McMaster ML, Lindor CJ, Greene MH. Concise handbook of familial cancer susceptibility syndromes - second edition. J Natl Cancer Inst Monogr 2008(38):1-93.

11. Clericuzio CL. Recognition and management of childhood cancer syndromes: a systems approach. Am J Med Genet 1999;89:81-90.

12. Heald B, Moran R, Milas M, Burke C, Eng C. Familial adenomatous polyposis in a patient with unexplained mental retardation. Nat Clin Pract Neurol 2007;3:694-700.

13. Sweet K, Willis J, Zhou XP, et al. Molecular classification of patients with unexplained hamartomatous and hyperplastic polyposis. JAMA 2005;294: 2465-2473. 
14. Finch R, Moore HG, Lindor N, et al. Familial adenomatous polyposis and mental retardation caused by a de novo chromosomal deletion at $5 \mathrm{q} 15-$ q22: report of a case. Dis Colon Rectum 2005;48:2148-2152.

15. Venturin M, Guarnieri P, Natacci F, et al. Mental retardation and cardiovascular malformations in NF1 microdeleted patients point to candidate genes in 17q11.2. J Med Genet 2004;41:35-41.

16. Bejjani BA, Saleki R, Ballif BC, et al. Use of targeted array-based CGH for the clinical diagnosis of chromosomal imbalance: is less more? Am J Med Genet A 2005;134:259-267.
17. Ballif BC, Theisen A, Coppinger J, et al. Expanding the clinical phenotype of the 3q29 microdeletion syndrome and characterization of the reciprocal microduplication. Mol Cytogenet 2008;1:8.

18. Shaffer LG, McCaskill C, Han JY, et al. Molecular characterization of de novo secondary trisomy 13. Am J Hum Genet 1994;55:968-974.

19. Albrecht P, Ansperger-Rescher B, Schuler A, Zeschnigk M, Gallie B, Lohmann DR. Spectrum of gross deletions and insertions in the RB1 gene in patients with retinoblastoma and association with phenotypic expression. Hum Mutat 2005;26:437-445. 